\title{
PERSPECTIVAS SOBRE POLÍTICAS PÚBLICAS DE INCLUSÃO DIGITAL E FOMENTO ASS CIDADES INTELIGENTES
}

\author{
PERSPECTIVES ON PUBLIC POLICIES FOR DIGITAL \\ INCLUSION AND FOSTERING INTELLIGENT CITIES \\ Yanko Marcius de Alencar Xavier ${ }^{1}$ \\ Patrícia Borba Vilar Guimarães ${ }^{1}$ \\ Douglas da Silva Araújo ${ }^{1}$
}

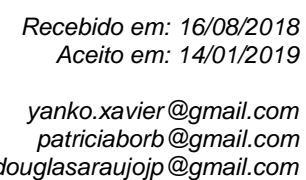

Resumo: Diante o efervescente debate que gira em torno da consolidação de cidades inteligentes no Brasil, a inclusão digital, consubstanciada no acesso às tecnologias de informação e comunicação (TICs), desponta como um fenômeno essencial para atender o "novo" modelo de gestão urbana participativa característica das smart cities ou cidades inteligentes. Nessa perspectiva, este ensaio objetiva analisar políticas públicas gestadas pelo Estado Brasileiro, mesmo aquelas que estão em fase embrionária, como projetos de lei, que intencionem inserir o Brasil na sociedade da informação (cibersociedade) de modo a incentivar a inclusão digital e, por via de consequência, fomentar a concretização de cidades inteligentes. Ao final, concluiu-se que o Poder Público assume papel importantíssimo na promoção de ações que visem à inclusão digital, como é o caso das isenções tributárias, além de se revelar necessária a evolução e desenvolvimento da própria legislação para acompanhar as novas formas de sociabilidade provenientes da "nova sociedade virtual" (cibersociedade) e para democratizar o acesso à internet, e mais ainda, a internet de qualidade.

Palavras-chave: Inclusão digital. Acesso à internet. Gestão urbana participativa. Smart cities. Cibersociedade.

\begin{abstract}
In the face of an effervescent debate about the consolidation of intelligent cities in Brazil, digital inclusion, embodied in the access to information and communication technologies (ICTs), emerges as an essential phenomenon to meet the "new" model of participatory urban management of smart cities or smart cities. In this perspective, this essay aims to analyze public policies developed by the Brazilian State, even those that are in an embryonic phase, such as bills, that intend to insert Brazil into the information society (cybersociety) in order to encourage digital inclusion and, consequently, to promote the realization of smart cities. In the end, it was concluded that the Public Power plays a very important role in the promotion of actions aimed at digital inclusion, as is the case of tax exemptions, besides proving necessary the evolution and development of the legislation itself to follow the new forms of sociability coming from the "new virtual society" (cybersociety) and to democratize access to the internet, and even more, the quality internet.
\end{abstract}

Keywords: Digital inclusion. Internet access. Participatory urban management. Smart cities. Cybersociety.

\section{NOÇÕES CONCEITUAIS SOBRE SMART CITIES}

Embora o fenômeno smart cities seja um assunto em efervescência no Brasil e no mundo, não há na literatura um conceito pacífico e sedimentado para as famosas cidades inteligentes.

\footnotetext{
${ }^{1}$ Universidade Federal do Rio Grande do Norte - UFRN - Natal - Rio Grande do Norte - Brasil
} 
Sob o enfoque empresarial, as cidades inteligentes apresentam-se como alvo de investimentos (presentes e futuros), abrindo espaço para um ambiente competitivo e lucrativo ao incentivar a atuação de pequenas empresas (startups) e multinacionais. Paralelamente, é crescente a preocupação em torno da inserção da tecnologia no ambiente urbano, no meio ambiente, na democracia, transparência e qualidade de vida.

Ao "elevar" uma cidade ao rótulo de smart city, muitas vezes o Poder Pública age de forma a atrair investimentos, fomentando uma espécie de empresarialização da governança urbana e de emergência de espaços urbanos neoliberais onde as empresas globais de tecnologia vendem as suas soluções aos governos locais (HOLLANDS, 2008).

Nesse viés, as cidades inteligentes podem vir a se transformar a em centros comerciais, pautados no lucro, onde a tecnologia, além de aprofundar as desigualdades, funciona como mecanismo de acúmulo de capital, sem qualquer comprometimento com o desenvolvimento humano e social.

Idealmente as soluções "smart" para uma cidade deveriam ser elaboradas dentro do planejamento urbano estratégico, com visão e valores fundamentados na participação popular, porém, diante da urgência por melhorias urbanas, a pressão do setor privado e falta de gestores preparados para entender todos os aspectos desse tipo de projeto, fazem com que se adotem soluções de forma desarticulada (FIGUEIREDO, 2016). Ou seja, corre-se o risco, na tentativa de concretização de cidades inteligentes, de ser deixado de lado um dos principais aspectos de sua constituição que é a participação popular na gestão urbana, intermediada pelos recursos tecnológicos.

Com o advento das cidades inteligentes, surge uma nova forma de gentrificação relacionada à exclusão de parcela da população que não possui habilidades suficientes para lidar com a tecnologia (exclusão social) (HOLLANDS, 2008). Essa nova forma de gentrificação [digital] não tem nada a ver com o alto custo dos imóveis ou com o custo de vida em si, mas sim com a exclusão de certas pessoas do processo de desenvolvimento da cidade (PALIOLOGO e GOMES, 2017). Os adeptos a essa corrente mais pessimista com a tecnologia consideram que os meios eletrônicos aprofundam as diferenças [sociais] entre os que têm recurso para participar [do processo decisório] e os que não têm (BEST e KRUEGER, 2005).

Sobre essa ideia de empresarialização das smart cities:

Observa-se o predomínio de projetos "smart" específicos em detrimento do âmbito maior do planejamento, acompanhado da expectativa de que esses esforços particularizados convergiriam naturalmente para gerar uma "smart city", como se ela não passasse de uma hiper-somatória de "smart projects". Essa ideia, ingênua em sua simplificação, fortalecida pelo modelo neoliberal e empresarial de gestão das cidades, em que se tornar "smart" é praticamente um esforço de branding, visando à conquista de uma certificação que traz maior competitividade frente a outras cidades (FIGUEIREDO, 2016, p. 07).

Dessa forma, as smart cities não podem ser restritas aos campos do lucro, da competitividade e dos investimentos por parte do empresariado. As cidades inteligentes devem ser pensadas de 
forma horizontal, onde o mercado, o Estado e a sociedade "lucrem" com a prestação de serviços públicos eficientes, a partir de um modelo de governança participativa, em que a tecnologia seja uma facilitadora desse diálogo, e não apenas uma espécie de commodity.

Ressalte-se que este ensaio não pretende desvencilhar o pilar econômico do qual também se erige o conceito de cidades inteligentes, pelo contrário, pretende-se sim dissociar o referido conceito da ideia de lucro puro, abrindo espaço para discussão das cidades inteligentes como fenômeno auxiliar do desenvolvimento humano e sustentável.

Nesse viés desenvolvimentista, uma cidade inteligente se forma quando investimentos em capital humano e social e tradicional (transporte) e moderna (TIC) infraestruturas tecnologias de comunicação alimentam um crescimento econômico sustentável e qualidade de vida, com uma gestão sábia dos recursos naturais por meio de uma governança participativa. (CARAGLIU; DEL BO; NIJKAMP, 2011 apud ABDALA et. al., 2014).

As cidades inteligentes têm foco em um modelo particularizado, com visão moderna do desenvolvimento urbano e que reconhecem a crescente importância das TICs no direcionamento da competitividade econômica, sustentabilidade ambiental e qualidade de vida geral (DUTTA, 2011).

A partir desses conceitos é possível identificar um movimento de alinhamento da literatura ao desenvolvimento social e a gestão urbana inclusiva, isso porque "é importante que as oportunidades de uma cidade inteligente não atropelem questões notáveis como a desigualdade social, os iletrados tecnológicos, as diferenças de acesso geracional e até mesmo por gênero" (TAMBELLI, 2008, p. 12), bem como é necessário que essas novas cidades estimulem "a efetiva participação dos cidadãos e o esforço e a utilização conjuntos das distintas inteligências - humana, coletiva e artificial - esta última pela utilização das Tecnologias da Informação e Comunicação (TICs)" (CURY e MARQUES, 2017, p. 103).

Komninos (2008), ao elencar três níveis de uma cidade inteligente, coloca as pessoas (inteligência humana) no início do processo de constituição de smart city.

O Banco Interamericano de Desenvolvimento (BID) define Cidade Inteligente como "aquela que coloca as pessoas no centro do desenvolvimento e as tecnologias de informação e comunicação na gestão urbana, e utiliza estes elementos como ferramentas para estimular o desenho de um governo efetivo que inclui o planejamento colaborativo e a participação cidadã" (ANDRADE e FRANCESCHINI, 2017, p. 3852).

Depreende-se dessa análise inicial que no processo de "smartização" de uma cidade é imprescindível a inclusão dos cidadãos nos processos decisórios (smart governance), com a tecnologia funcionando como uma espécie de "ponte" de aproximação entre Poder Público e a população.

A par dessa discussão inicial, o presente ensaio tem como premissa o fato de que são necessárias políticas públicas que impliquem no fomento à inclusão digital, apresentando-se como indispensáveis no contexto de participação popular nas cidades inteligentes.

Consigne-se que este trabalho não tem um caráter exaustivo no sentido de elencar todas as políticas públicas que possam influir na democratização do acesso à tecnologia no âmbito das smart cities, mas sim sugestivo, visando fornecer diretrizes às futuras ações do Poder Público. 


\section{CIBERESPAÇO, INCLUSÃO DIGITAL E CIDADANIA}

Novos conceitos emergiram com a ascensão do uso da Internet e de outras TIC, como ciberespaço [...] cidadania digital (NEVES, 2010, p. 145-146) e inclusão digital.

O ciberespaço é "[...] uma nova noção de espaço, em que o físico e o virtual se influenciam um ao outro, lançando as bases para a emergência de novas formas de socialização, novos estilos de vida e novas formas de organização social" (CARDOSO, 1998, p. 116).

O ciberespaço dá origem a uma sociedade virtual (cibersociedade) ao fazer uso dos recursos digitais disponíveis na comunicação entre as pessoas (FARIAS, 2016). Sobre o tema, Velloso (2008, p. 108) aduz:

O cenário virtual, ou o ciberespaço, passa a se constituir em importante território da esfera social, a ágora eletrônica contemporânea, que possibilita dar visibilidade aos fatos da vida privada, tratar fatos e fenômenos da esfera pública e sobretudo redimensionar a esfera social.

Apesar de o ciberespaço apresentar-se como uma "nova sociedade", marcada pela ingerência das TICs, é válido registrar que há uma espécie de consenso no sentido que o ciberespaço não se constitui, por si mesmo, em garantia de conquista de democracia, igualdade e ou liberdade [...] persistindo as desigualdades correlações de forças [...] de caráter simbólico (VELLOSO, 2008, p. 108).

No ciberespaço, a desigualdade também é gerada pela falta de condições de inserção plena de todos em uma nova forma de ser da sociedade: uma sociedade tecnologicamente avançada (FARIAS, 2016, p. 03). Nesse contexto, as políticas públicas de inclusão digital se colocam cada vez mais como alicerce de fortalecimento democrático e distribuição das condições de produção no universo capitalista digital (LOURENÇO; CARVALHO, 2016, p. 09). A inclusão digital passou a se apresentar como uma nova condição necessária para a inclusão social na "sociedade rede" ou "cibersociedade" (FARIAS, 2016, p. 07).

Em se tratando de acesso às tecnologias digitais, Silveira (2001) observa que a inclusão social passa pela inclusão digital, uma vez que é pela rede mundial de computadores - a internet -, que circula a informação.

Do ponto de vista ético, a inclusão digital é vista como uma ação promotora da conquista da "cidadania digital", a qual contribuirá para uma sociedade mais igualitária, com a expectativa da inclusão social (RIBEIRO, 2007). Sobre essa influência dos meios digitais numa nova perspectiva de inclusão social, Farias (2016, p. 07) alude:

A inclusão social hoje demanda maior complexidade que em décadas anteriores na medida em que a inclusão digital passa a ser indispensável para podermos desfrutar tudo o que as sociedades tecnologicamente avançadas propiciam. É a Inclusão Digital, em grande medida, responsável pela participação efetiva dos cidadãos e cidadãs na sociedade atual, denominada "Sociedade Rede" por uns, e por outros, "Sociedade da Informação", "Sociedade do Conhecimento" e "Cibersociedade". 
A inclusão digital, nesse ínterim, deve ser entendida como a disponibilização, acesso e uso das tecnologias computacionais, especialmente da internet, visando a construção do conhecimento, a consolidação da autonomia e da cidadania (VILELA JUNIOR; VILARTA; 2014, p. 34-35).

No âmbito da sociedade de informação, o conceito de cidadania está atrelado aos desafios oriundos do progresso das tecnologias digitais que reconfiguram o padrão das relações sociais, o que leva parte da literatura a definir como um novo tipo de cidadania (SEBASTIÃO; PACHECO; SANTOS, 2012, p. 33). Portanto, a cidadania digital também apresenta alguns desafios como a exclusão digital, questões de segurança e excesso de informação (QUENTAL, 2015).

A partir das premissas dispostas acima, é inegável que o ciberespaço, a cidadania digital e a inclusão digital são debates que permeiam a implantação de cidades inteligentes.

Pode-se depreender das ponderações feitas sobre os conceitos apresentados, que todas passam por "desafios de implementação" associados à ideia de inclusão digital. Por isso revela-se crucial analisar as políticas públicas gestadas pelo Estado, mesmo aquelas que estão em fase embrionária, como projetos de leis, as quais intencionem inserir o Brasil na sociedade da informação (cibersociedade) de modo a fomentar a inclusão digital.

\section{PERSPECTIVAS PARA A INCLUSÃO DIGITAL NO BRASIL}

A inclusão digital representa a defesa dos direitos à universalização do acesso à Internet para inserção no ciberespaço, através da promoção de políticas públicas favoráveis à redução de custos para aquisição de equipamentos (hardware) [...] e expansão do acesso público (PIRES, 2005).

No âmbito as políticas públicas de inclusão digital, merece destaque a Portaria 7.154, de 06 de dezembro de 2017, elaborada pelo Ministério de Ciência, Tecnologia, Inovações e Comunicações (MCTIC), que estabeleceu parâmetros ao novo programa de conectividade, intitulado Internet para Todos² $^{2}$ A norma trata-se de uma reformulação do GESAC (Governo Eletrônico - Serviço de Atendimento ao Cidadão), programa do Governo Federal que "oferece gratuitamente conexão à internet em banda larga - por via terrestre e satélite - a telecentros, escolas, unidades de saúde, aldeias indígenas, postos de fronteira e quilombos. ${ }^{3 "}$.

O programa GESAC tem como objetivos promover a inclusão digital, por meio do fornecimento de conexão à internet em banda larga, inclusive naquelas localidades onde inexista oferta adequada de conexão à Internet; apoiar comunidades em estado de vulnerabilidade social, localizadas em áreas rurais, remotas e nas periferias urbanas, oferecendo acesso a serviços de conexão à internet, promovendo a inclusão digital e social e incentivando as ações de governo eletrônico; ampliar o provimento de acesso à internet em banda larga para instituições públicas, com prioridade para regiões remotas e de fronteira; apoiar órgãos governamentais em ações de governo

\footnotetext{
2 Ministério da Ciência, Tecnologia, Inovações e Comunicações. Inclusão Digital. Disponível em: <http://www.mctic.gov.br/mctic/opencms/comunicacao/SETEL/inclusao_digital/>. Acesso em: 01 jun. 2018.

${ }^{3}$ Ministério do Planejamento, Desenvolvimento e Gestão. Gestão Digital. Programa GESAC. Disponível em: <https://www.governodigital.gov.br/cidadania/inclusao-digital/programa-gesac >. Acesso em: 01 jun. 2018.
} 
eletrônico; contribuir para a ampliação do acesso à internet em consonância com outros programas de governo, em especial com o Plano Nacional de Banda Larga - PNBL.

Uma interessante observação sobre a Portaria 7.154/17, é que a mesma previa, em seu art. 9º, II, uma espécie de atrativo aos prestadores de serviços que era a isenção de ISS na oferta do serviço de acesso à internet. Contudo, o referido artigo foi revogado pela Portaria MCTIC № 1.989, de 12.04.2018, que em sua nova redação não mais previu a referida isenção.

Winkler (2005), em estudo realizado poucos anos após a criação do programa, elencou alguns problemas de implementação do programa GESAC, dentre eles a má distribuição dos pontos de acesso à internet, computadores "insuficientes", apresentando "restrições de hardware e de software", tecnologicamente desatualizados, além de contradições existentes quanto à sustentabilidade, uma vez que o programa previu o acesso à internet de forma gratuita, porém em alguns pontos as ONGS cobravam para permitir o uso dos computadores.

Em que pese tais entraves, o GESAC já alcançou resultados significativos. Tramontin e Borges (2007) realizaram estudo sobre a contribuição do programa GESAC para a inclusão digital dos cidadãos do Rio Grande do Norte, através de pesquisa de campos e aplicação de questionário, nos locais onde o programa foi instalado, em que constataram que a implantação do GESAC no RN permitiu inclusão digital nos pontos de presença instalados, facilitando o acesso da população às informações e serviços do governo, fortalecimento a consciência de cidadania dos moradores e melhorando o nível de informação das comunidades.

Outra importante política de inclusão digital está materializada no Convênio ICMS 141, de 14 de dezembro de 2007, o qual autoriza os Estados e o Distrito Federal a conceder isenção de ICMS na prestação de serviço de comunicação no âmbito do Programa Governo Eletrônico de Serviço de Atendimento do Cidadão (GESAC) ${ }^{4}$. Em sua cláusula primeira, o convênio autoriza os Estados e o Distrito Federal a concederem isenção do ICMS na prestação de serviço de comunicação referente ao acesso à internet e ao de conectividade em banda larga no âmbito do Programa Governo Eletrônico de Serviço de Atendimento do Cidadão - GESA, instituído pelo Governo Federal.

Um exemplo de concretização do convênio foi quando a Prefeitura de São Paulo, em 2010, fechou com a empresa Net e o Grupo Telefônica uma parceria que habilitava as empresas a oferecer pacotes completos de acesso rápido à rede mundial de computadores dentro do Programa Banda Larga Popular, do governo paulista. O programa, lançado no ano anterior a parceria em referência, objetivava facilitar o acesso da população à internet de alta velocidade, zerando o ICMS para as operadoras que aderissem a ele. Em contrapartida, deveria ser oferecido um pacote com um modem, instalação e serviços de provedor com velocidade entre 200 kbps e 01 Mbps, ao valor máximo $R \$$ 29,80 por mês, sem restrições de horário ou tráfego de dados. Até julho 2010, o programa paulista estava disponível apenas para pessoas físicas (MENDES, 2010). Posteriormente, o programa foi

\footnotetext{
4 Ministério da Fazenda. Conselho Nacional de Política Fazendária. Disponível em:
} <https://www.confaz.fazenda.gov.br/legislacao/convenios/2007/CV141_07>. Acesso em: 01 jun. 2018. 
ampliado, estendendo o beneficio da redução a zera da alíquota do ICMS aos pacotes de 1,5 e 2 $\mathrm{Mb}^{5}$.

Desse modo, percebe-se o quão é importante o desenvolvimento de programas destinados à democratização do acesso à internet e de incentivo à inclusão digital, e mais, a necessidade desses programas alcançarem a população de baixa renda e as localidades de difícil acesso. A difusão de uma cultura digital é necessária e precedente à própria implantação de um governo eletrônico (egov), e por consequência das cidades inteligentes, sob pena da interação virtual (on-line) entre governo e população repetir os mesmos erros dos tradicionais processos participativos.

Em trabalho desenvolvido sobre o Programa Governo Eletrônico, que objetivou demonstrar o grau de adesão do cidadão a esses serviços (internet), a fim de propor uma reflexão sobre a inclusão digital, Henriques et al (2016) concluiu, com base nos dados de proporção colhidos no site "CETIC.br", que há uma necessidade premente de investimentos em projetos de inclusão digital e democratização do acesso à internet para o sucesso do Governo Eletrônico, além de uma mudança cultural que reduza as resistências em relação aos benefícios das novas tecnologias, tornando imperativa a elaboração de políticas públicas destinadas à expansão do acesso à internet, principalmente às áreas mais pobres e ao público com menor escolaridade.

Diferentemente dos programas de inclusão digital listados acima, os quais mais se alinham à definição de política pública de governo ${ }^{6}$, as leis, elaboradas com a mesma finalidade, são tão quanto ou até mais eficientes frente a uma modernidade tecnológica que remodela os laços sociais, criando novos conflitos. Isto é, as leis por serem políticas públicas que envolvem em sua constituição processos burocráticos, com tramitação pelas casas legislativas e/ou outras instâncias de discussão, representando exemplo de políticas de Estado, revestem-se de um caráter mais perene, considerando que qualquer mecanismo de revogação ou reformulação também será mais burocrático, além de estarem menos associadas a uma única agenda político-partidária, tendo em vista que a sua concepção depende de outros poderes e de várias instâncias de debate. Sobre políticas públicas de Estado, ensina Almeida (2016, n.p.):

Políticas de Estado, por sua vez, são aquelas que envolvem as burocracias de mais de uma agência do Estado, justamente, e acabam passando pelo Parlamento ou por instâncias diversas de discussão, depois que sua tramitação dentro de uma esfera (ou mais de uma) da máquina do Estado envolveu estudos técnicos, simulações, análises de impacto horizontal e vertical, efeitos econômicos ou orçamentários, quando não um cálculo de custo-benefício levando em conta a trajetória completa da política que se pretende implementar. $O$ trabalho da burocracia pode levar meses, bem como o eventual exame e discussão no Parlamento, pois políticas de

\footnotetext{
${ }^{5}$ Governo do Estado de São Paulo. SP amplia Banda Larga Popular e dobra velocidade da internet. Disponível em: $\quad<$ http://www.saopaulo.sp.gov.br/spnoticias/ultimas-noticias/sp-amplia-banda-larga-popular-e-dobravelocidade-da-internet/>. Acesso em: 01 jun. 2018.

${ }^{6}$ Políticas de governo são aquelas que o Executivo decide num processo bem mais elementar de formulação e implementação de determinadas medidas para responder às demandas colocadas na própria agenda política interna - pela dinâmica econômica ou política - parlamentar, por exemplo - ou vindos de fora, como resultado de eventos internacionais com impacto doméstico. Elas podem até envolver escolhas complexas, mas pode-se dizer que o caminho entre a apresentação do problema e a definição de uma política determinada (de governo) é bem mais curto e simples, ficando geralmente no plano administrativo, ou na competência dos próprios ministérios setoriais (ALMEIDA, 2016, n.p.).
} 
Estado, que respondem efetivamente a essa designação, geralmente envolvem mudanças de outras normas ou disposições pré-existentes, com incidência em setores mais amplos da sociedade.

Nessa perspectiva, ainda em fase embrionária, encontra-se em trâmite no Congresso Nacional os Projetos de Lei n.. 5319/2016 (Câmara dos Deputados) e n.ำ 431/2014 (Senado Federal), ambos visam acrescer dispositivo à Lei Federal no 9.472, de 16 de julho de 1997, reconhecendo o serviço de acesso à internet em banda larga como essencial.

Em que pese à existência de divergência doutrinária sobre a possiblidade ou não de interrupção de serviço público essencial, que não é objetivo deste estudo tratar sobre essa discussão, é extremamente válido ressaltar a corrente que sustenta a impossibilidade do corte no fornecimento de serviço público considerado essencial, em razão da urgência e necessidade do serviço, com a qual se alinha os ensinamentos de Di Pietro (2008, p. 175):

[...] o usuário tem direito à prestação do serviço; se este lhe for indevidamente negado, pode exigir judicialmente o cumprimento da obrigação pelo concessionário; é comum ocorrerem casos de interrupção na prestação de serviços como os de luz, água e gás, quando o usuário interrompe o pagamento; mesmo nessas circunstâncias, existe jurisprudência no sentido de que o serviço, sendo essencial, não pode ser suspenso, cabendo ao concessionário cobrar do usuário as prestações devidas, usando das ações judiciais cabíveis.

Tornando-se essencial o serviço de acesso à internet em banda larga, o Poder Público deverá garantir a continuidade de sua prestação. Quando essencial, o serviço público está associado à ideia de indispensabilidade, necessidade premente e/ou inafastável.

É interessante observar que a Lei Federal n.․ 12.965/2014, conhecida como Marco Civil da Internet, já tinha estabelecido em seu artigo $7^{\circ}$ que "o acesso à internet é essencial ao exercício da cidadania", porém, não fez menção expressa ao fornecimento do respectivo serviço na modalidade banda larga e muito menos acerca de sua essencialidade. Apesar dessa ausência de previsão, o Marco Civil da Internet representou um enorme avanço no ordenamento jurídico brasileiro, ao dispor sobre princípios, direitos e deveres dos usuários da internet, além de incentivar a inclusão digital por meio de iniciativas públicas.

A Lei n. 12.965/14, além de vincular a noção de informação com a liberdade de expressão, de comunicação e de criação intelectual como expressão de direitos humanos, encarregou o Poder Público em promover ações de fomento à cultura digital e promoção da internet como ferramenta social, visando promover a inclusão digital; reduzir as desigualdades regionais no acesso às TICs e no seu uso, fomentando a produção e circulação de conteúdo nacional (WACHOWICZ, 2015).

Outro projeto de lei em trâmite na Câmara dos Deputados, relevante quando se fala em inclusão digital, é o PL n.ำ 7861/2017 (Apensado ao PL n.ำ1481/2007). O projeto visa alterar a Lei n.. 9.394, de 20 de dezembro de 1996, que estabelece as diretrizes e bases da educação nacional, para dispor sobre a inclusão digital, acrescendo como dever do Estado a implantação da infraestrutura de conectividade por meio de Wifi aberto e banda larga até as salas de aula, complementada pelo 
desenvolvimento de uma cultura digital, que inclui o ensino e o acesso a habilidades, ferramentas e plataformas.

A justificativa apresentada pelo projeto de lei em questão ressalta a necessidade de contribuir para a formação do cidadão do século XXI, inserido num mundo cada dia mais digital, devendo o Estado, através da educação, garantir as novas exigências do mundo contemporâneo (BRASIL, 2017).

\section{CONSIDERAÇÕES FINAIS}

A inclusão digital pode ser considerada como um direito a partir do momento que, por suas características, ela não é somente uma necessidade, mas um valor que acrescenta ao ser humano potencialidades e maneiras de se realizar como tal, realçando e ativando outros direitos inerentes à sua condição, como a liberdade, a igualdade, a dignidade, etc. (GONÇALVES, 2012).

No âmbito das cidades inteligentes, é impossível imaginar uma plena democracia sem que esse debate não esbarre necessariamente na inclusão digital, a qual não diz respeito apenas ao simples acesso à tecnologia, relacionando-se também com a construção e a vivência de uma cultura de rede como elementos fundamentais para o exercício da cidadania na sociedade contemporânea (MELO; TEIXEIRA, 2007).

Com o advento das cidades inteligentes, o debate em torno da inclusão/exclusão digital ganhou ainda mais espaço, especialmente em razão de se enxergar uma espécie de "gentrificação digital", consubstanciada no acesso desigual de parcela da população aos recursos tecnológicos. Nesse contexto, o Poder Público assume papel importantíssimo no que diz respeito ao desenvolvimento de ações que visem superar esse "novo" processo segregacionista.

Com efeito, este estudo buscou evidenciar como as isenções tributárias podem ser eficazes no incentivo às ações de inclusão digital. Conforme sugerido por Sousa (2011), ao ponderar sobre o assunto, qualquer aparelho criado para permitir o acesso à internet deveria ser beneficiado com redução de alíquotas de impostos, sobretudo quando fossem voltados às classes de baixa renda. $O$ autor sustenta que tal ação poderia auxiliar no equacionamento do problema de exclusão digital no Brasil.

Nessa perspectiva, pôde se observar que os programas desenvolvidos pelo Governo Federal listados neste ensaio, em especial o GESAC, apesar dos entraves, foram eficazes em certa medida, geraram índices positivos de inclusão digital, principalmente para a classe mais baixa e para as regiões de difícil acesso (objetivos do programa), contribuindo para o fortalecimento de uma cultura digital e também para a cibercidadania.

É válido também ressaltar a necessidade de que os programas de incentivo à inclusão digital, além de comporem uma agenda política de governo, sejam transformados em políticas de Estado, como aconteceu com o Marco Civil da Internet, e que deve também ser observado com relação aos projetos de lei em trâmite no Congresso Nacional que visam tornar essencial o serviço de acesso à internet em banda larga, obrigar o Estado a implantar infraestrutura de conectividade por meio de Wifi 
aberto, dentre outros projetos que objetivam aprimorar a legislação e incentivar o desenvolvimento de uma cultura digital.

Apesar dos desafios a inclusão digital ainda serem muitos, nos últimos anos esse cenário tem ganhado especial avanço, ao passo que a tendência demonstrada por esta pesquisa é de incentivo por parte do Governo Federal a programas de inclusão digital, além de o próprio Poder Legislativo está dando mais atenção às leis que visam regular as novas formas de sociabilidades oriundas da sociedade virtual ou cibersociedade, o que pôde ser visto com a aprovação do Marco Civil da Internet e com a proposição de outros projetos de lei, em curso nas casas legislativas, que planejam atribuir ao Estado a responsabilidade no fornecimento de internet de qualidade a todos.

\section{REFERÊNCIAS}

ABDALA, L.; SCHREINER, T.; COSTA, E. M.; SANTOS, N. Como as cidades inteligentes contribuem para o desenvolvimento de cidades sustentáveis? Uma revisão sistemática de literatura. Int. J. Knowl. Eng. Manag, v. 3, n.5, p. 98-120, 2014.

ALMEIDA, Paulo Roberto de. Sobre Políticas de Governo e Políticas de Estado: distinções necessárias. Instituo Millenium - Centro de pensamento. 07/04/2016. Disponível em: $<$ https://www.institutomillenium.org.br/artigos/sobre-politicas-de-governo-e-politicas-de-estadodistincoes-necessarias/>. Acesso em: 01 jun. 2018

ANDRADE, Elisabete Agrela; FRANCESCHINI, M. C. O Direito à Cidade e as Agendas Urbanas Internacionais: uma análise documental. Ciência \& Saúde Coletiva, v. 22, p. 3849--3858, 2017.

BEST, Samuel J.; KRUEGER, Brian S. Analyzing the Representativeness of Internet Political Participation. Political Behavior 27:183-216. 2005.

BRASIL. Câmara dos Deputados. Projetos de Lei. Pesquisa Simplificada. Disponível em: <http://www.camara.leg.br/buscaProposicoesWeb/pesquisaSimplificada>. Acesso em: 01 jun. 2018.

CARDOSO, Gustavo. Para uma sociologia do ciberespaço: comunidades virtuais em português. Oeiras, Portugal: Editora Celta, 1998.

CARVALHO, Juliano M.; LOURENCO, A. L. Inclusão Digital e Cidadania: um olhar sobre o Programa Acessa SP, seus potenciais e limites. In: Intercom - Sociedade Brasileira de Estudos Interdisciplinares da Comunicação, 2016, São Paulo. XXXIX Congresso Brasileiro de Ciências da Comunicação, 2016.

CURY, Mauro José Ferreira; MARQUES, Josiel Alan Leite Fernandes. A Cidade Inteligente: uma reterritorialização / Smart City: A reterritorialization. Redes (Santa Cruz do Sul. Online), v. 22, p. 102$117,2017$.

DI PIETRO, Maria Sylvia Zanella. Direito Administrativo. 21. ed. São Paulo: Atlas, 2008.

DUTTA, S. (Ed.). (2011). The Global Innovation Index 2011: accelerating growth and development. Fontainebleau: INSEAD.

FARIAS, Antônia de Araújo. Inclusão Digital e Cidadania na sociedade da informação e do conhecimento. II Congresso Internacional de Educação Inclusiva - II CINTEDI. Anais... V. 1, 2016, ISSN 2359-2915. Disponível em:

<http://editorarealize.com.br/revistas/cintedi/resumo.php?idtrabalho=787>. Acesso em: 20 mai. 2018.

FIGUEIREDO, G. M. P. Cidades inteligentes no contexto brasileiro: a importância de uma reflexão crítica. In: IV ENANPARQ - Encontro da Associação Nacional de Pesquisa e Pós-graduação em Arquitetura e Urbanismo, 2016, Porto Alegre. Anais do IV ENANPARQ - Encontro da Associação Nacional de Pesquisa e Pós-graduação em Arquitetura e Urbanismo. Porto Alegre: PROPAR/UFRGS, 
2016. Disponível em: <https://www.anparq.org.br/dvd-enanparq-4/SESSAO\%2044/S44-04FIGUEIREDO,\%20G.pdf>. Acesso em: 20 mai. 2018.

GONÇALVES, Victor Hugo Pereira. Inclusão Digital como Direito Fundamental. Início: 2010. Dissertação (Mestrado em Direito) - Universidade de São Paulo. Flávia Inês Schilling (Orientador). Publicação: 12/11/2012. Disponível em: <http://www.teses.usp.br/teses/disponiveis/2/2140/tde30102012-092412/pt-br.php>. Acesso em: 20 jun. 2018.

HENRIQUES, Juliana de Souza; CANUTO, Luanda Costa; MORAES, Samantha Araújo de. 0 Governo Eletrônico no Brasil: a adesão do cidadão. Artigo científico. Universidade Federal Fluminense. Disponível em: <https://app.uff.br/riuff/handle/1/1905>. Acesso em: 20 jun. 2018

HOLLANDS, Robert G. Will the real smart city please stand up? London: City, 2008, v.12, n.3, p.303-320. DOI: $10.1080 / 13604810802479126$.

KOMNINOS, N. Cidades Inteligentes - Sistemas de Inovação e Tecnologias da Informação ao serviço do Desenvolvimento das Cidades. 2008. Disponível em: <http://www.urenio.org/wpcontent/ uploads/2008/11/cidades-inteligentes.pdf>. Acesso em: 20 mai. 2018.

MENDES, Patrícia. Internet Popular. Julho 2010. Biblioteca Digital Fundação Getúlio Vargas (FGV). Disponível em: <encurtador.com.br/jyzL5>. Acesso em: 20 mai. 2018.

NEVES, Bárbara Barbosa. Cidadania Digital? Das cidades digitais a Barack Obama. Uma abordagem crítica. In: Cidadania Digital. Isabel Salema Morgado António Rosas (orgs.). LabCom Books 2010. ISBN: 978-989-654-051-7. Disponível em: < http://www.labcom-

ifp.ubi.pt/ficheiros/20101103-morgado_rosas_cidadania_2010.pdf>. Acesso em: 01 jun. 2018.

PALIOLOGO, Nicholas Arena; GOMES, Daniel Machado. Direito à cidade e políticas públicas para a smart city. Revista de Direito Urbanístico, Cidade e Alteridade; e-ISSN: 2525-989X; Brasília; v. 3, n. 1, p. 19-35, 2017.

PIRES, Hindemburgo Francisco. A Geografia da Internet e do Ciberespaço na América Latina. In ENCONTRO DE GEÓGRAFOS DA AMÉRICA LATINA. X, 2005, São Paulo. Disponível em <http://cibergeo.org/artigos/GEOGRAFIADAINTERNET.pdf>. Acesso em: 01 jun. 2018.

QUENTAL, Carlos Alberto Torres. A mediação digital como suporte para a participação no contexto dos sindicatos de professores; 2015; Tese (Doutorado em Doutoramento em Ciências da Informação, especializ) - Universidade Fernando Pessoa; Orientador: Luis Manuel Borges Gouveia. Disponível em: <http://docplayer.com.br/5268851-Carlos-alberto-torres-quental-a-mediacao-digitalcomo-suporte-para-a-participacao-no-contexto-dos-sindicatos-de-professores.html >. Acesso em: 01 jun. 2018.

RIBEIRO, M. T. P.. Inclusão digital e cidadania. In: IX Jornada Multidisciplinar - Pensamento e Linguagem, 2007, Bauru/SP. IX Jornada Multidisciplinar - Pensamento e Linguagem. Bauru/SP: Canal 6, 2007. v. 1. p. 74-79.

SEBASTIÃO, Sónia; PACHECO, André; SANTOS, Mariana. Cidadania Digital e Participação Política: O Caso das Petições Online e do Orçamento Participativo. Estudos em Comunicação, vol. 11, pp. 31-51, 2012. Disponível em: <http://www.ec.ubi.pt/ec/11/pdf/EC11-2012Mai-02.pdf>. Acesso em: 01 jun. 2018.

SILVEIRA, S. A. Exclusão digital - a miséria na era da informação. São Paulo: Fundação Perseu Abramo, 2001.

SOUSA, R. A. F.. Futuros desafios para o programa nacional de banda larga. Radar: tecnologia, produção e comércio exterior, v. 15, p. 9-18, 2011. Disponível em:

$<$ http://repositorio.ipea.gov.br/bitstream/11058/5353/1/Radar_n15_Futuros.pdf>. Acesso em: 01 jun. 2018. 
TAMBELLI, Clarice Nassar. Smart Cities: uma breve investigação crítica sobre os limites de uma narrativa contemporânea sobre cidades e tecnologia. Instituto de Tecnologia e Sociedade do Rio ITS Rio; 2018. Disponível em: <https://itsrio.org/wp-

content/uploads/2018/03/clarice_tambelli_smartcity.pdf>. Acesso em: 01 jun. 2018.

TEIXEIRA, A. Canabarro; MARCON, Karina (org.). Inclusão digital: experiências, desafios e perspectivas. Passo Fundo: Ed.Universidade de Passo Fundo, 2009. 278p.

TRAMONTIN, Adriane; BORGES, D. F. Um caminho para a inclusão digital: o Programa GESAC. O\&S. Organizações \& Sociedade, v. 14, p. 167-184, 2007. Disponível em: <http://www.scielo.br/pdf/osoc/v14n42/10.pdf>. Acesso em: 01 jun. 2018.

VELLOSO, Ricardo Viana. O ciberespaço como ágora eletrônica na sociedade contemporânea. Ci. Inf. [online]. 2008, vol.37, n.2, pp.103-109. ISSN 0100-1965. Disponível em: <http://dx.doi.org/10.1590/S0100-19652008000200008>. Acesso em: 01 jun. 2018.

VILELA JUNIOR, G. B.; VILARTA, Roberto. Inclusão digital, cidadania e construção do conhecimento para a qualidade de vida. In: Roberto Vilarta. (Org.). Qualidade de Vida e Políticas Públicas: Saúde, Lazer e Atividade Física. 1ed.Campinas: IPES, 2004, v. 1, p. 27-40. Disponível em: <https://www.fef.unicamp.br/fef/sites/uploads/deafa/qvaf/qualidade_politicas_publicas_cap3.pdf>. Acesso em: 01 jun. 2018.

WACHOWICZ, Marcos. Cultura Digital e o Marco Civil da Internet: contradições e impedimentos jurídicos no acesso à informação. In: Adalberto Simão Filho, Newton De Lucca. (Org.). Direito e Internet III: Marco Civil da Internet. 1ed. São Paulo: Editora Quartier Latin, 2015, v. 1, p. 345-377.

WINKLER, Ingrid. Análise da implementação de políticas públicas brasileiras de Inclusão Digital. 2005. Dissertação (Mestrado em Administração) - Universidade Federal da Bahia, Salvador 2015.

\section{COMO CITAR ESSE DOCUMENTO:}

ARAÚJO, Douglas da Silva; GUIMARÃES, Patrícia Borba Vilar; XAVIER, Yanko Marcius de Alencar. Perspectivas sobre políticas públicas de inclusão digital e fomento às cidades inteligentes. Revista do Direito, Santa Cruz do Sul, v. 3, n. 56, jan. 2019. ISSN 1982-9957. Disponível em: $<$ https://online.unisc.br/seer/index.php/direito/article/view/12465>. Acesso em: doi:https://doi.org/10.17058/rdunisc.v3i56.12465. 